OPEN ACCESS

Edited by:

Renheng Wang,

Shenzhen University, China

Reviewed by:

Feng $\mathrm{Gu}$,

Jiangxi University of Science and

Technology, China

Lidong Sun,

Chongqing University, China

*Correspondence:

Jinlin Lu

jinlinlu@hotmail.com

Yansheng Yin

ysyin@shmtu.edu.cn

Specialty section:

This article was submitted to

Electrochemical Energy Conversion

and Storage,

a section of the journal

Frontiers in Energy Research

Received: 03 January 2022

Accepted: 24 January 2022

Published: 28 February 2022

Citation:

Xue L, Bao S, Yan L, Zhang Y, Lu J and

Yin Y (2022) MgO-Coated Layered Cathode Oxide With Enhanced

Stability for Sodium-Ion Batteries.

Front. Energy Res. 10:847818.

doi: 10.3389/fenrg.2022.847818

\section{MgO-Coated Layered Cathode Oxide With Enhanced Stability for Sodium- Ion Batteries}

\author{
Ling Xue ${ }^{2}$, Shuo $\mathrm{Bao}^{2}$, Ling Yan ${ }^{3}$, Yi Zhang ${ }^{1}$, Jinlin $\mathrm{Lu}^{1 *}$ and Yansheng Yin ${ }^{1 *}$ \\ ${ }^{1}$ Research Center for Corrosion and Erosion Process Control of Equipment and Material in Marine Harsh Environment, Guangzhou \\ Maritime University, Guangzhou Guangdong, China, ${ }^{2}$ School of Materials and Metallurgy, University of Science and Technology, \\ Liaoning, Anshan, China, ${ }^{3}$ State Key Laboratory of Metal Material for Marine Equipment and Application, Anshan, China
}

$\mathrm{Na}_{0.67} \mathrm{Ni}_{0.33} \mathrm{Mn}_{0.67} \mathrm{O}_{2}$ is a prospective layered cathode material for sodium-ion batteries owing to its low cost, ease of synthesis, and high specific capacity. However, due to direct contact with electrolytes during the cycling process, the cyclic stability is not satisfied. To address this issue, magnesium oxide (MgO) surface modification was performed in this study to improve the material's cycling properties. MgO layers of various thicknesses were successfully coated onto the cathode, and their electrochemical performances were thoroughly investigated. Among the as-prepared samples, the $2 \mathrm{wt} \% \mathrm{MgO}$-coated sample demonstrated the best rate capability and cycling stability. It had an initial reversible discharge capacity of $105 \mathrm{mAh} \mathrm{g}^{-1}$ in the voltage range from 2.0 to $4.5 \mathrm{~V}$ at $0.2 \mathrm{C}$ with a high cycle retention of $81.5 \%$. Electrochemical impedance spectroscopy (EIS) results showed that the $2 \mathrm{wt} \% \mathrm{MgO}$-coated electrode had the highest conductivity due to the smaller charge transfer resistance (Rct) value. All the test results show that the $\mathrm{MgO}$ modification improves the electrochemical properties of $\mathrm{Na}_{0.67} \mathrm{Ni}_{0.33} \mathrm{Mn}_{0.67} \mathrm{O}_{2}$ cathode material. This research could lead to the development of a promising strategy for improving the electrochemical performance of next-generation sodium-ion batteries.

Keywords: sodium-ion battery, layered cathode oxide materials, $\mathrm{MgO}$ modification, $\mathrm{Na}_{0.67} \mathrm{Ni}_{0.33} \mathrm{Mn}_{0.67} \mathrm{O}_{2}$, electrochemical properties

\section{INTRODUCTION}

Recently, the rapid development of electronic equipment and low-power electric vehicles has increased the demand for energy storage materials with high energy efficiency, abundant resources, and environmental friendliness (Kundu et al., 2015; González et al., 2016). Lithiumion batteries (LIBs) are currently recognized as an energy storage product with high energy density and good performance rating. However, given the massive consumption of lithium batteries, the shortage of lithium resources will inevitably be a serious problem (Lu et al., 2013; Peng et al., 2016). In contrast, sodium-ion batteries (SIBs) have the advantages of a wider source of raw materials, lower cost, and more safety than LIBs. In some energy storage fields with low energy density requirements, the shortage of lithium resources can be alleviated to a certain extent (Pu et al., 2019; Hakim et al., 2021). Moreover, the electrochemical performance of SIBs is mainly determined by the cathode material. Prussian blue analogues (Zhu et al., 2019; Du and Pang, 2021), organic compounds (Wang et al., 2014; Huang et al., 2017), polyanionic compounds (Essehli et al., 2020; Lv et al., 2021), and layered transition metal oxide (Yang and Wei, 2020; Zhao et al., 2021) as SIB cathode materials have been extensively researched. Most of them have the fatal issue of low average working voltage, which 


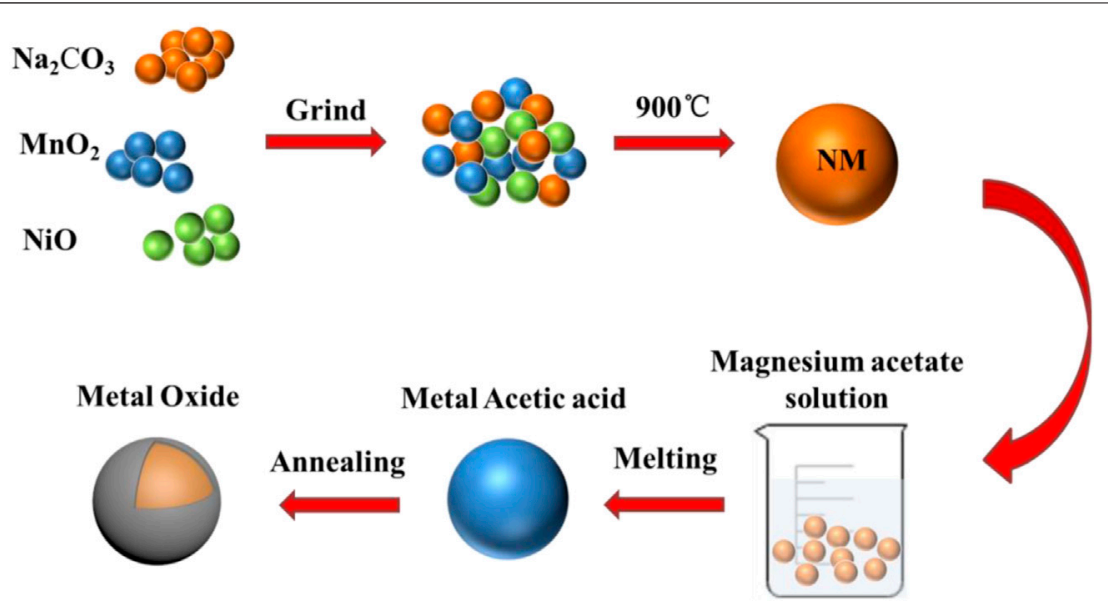

FIGURE 1 | Schematic diagram of MgO-coated NM cathodes.

severely restricts their energy density. Among them, layered transition metal oxides $\left(\mathrm{Na}_{\mathrm{x}} \mathrm{MO}_{2}\right)$ with high operating voltage and electrochemical capacity, such as P2-type(Kuan Wang et al., 2018; Kannan et al., 2021) and O3-type cathode materials (Rong et al., 2019), are deemed promising cathode material candidates for commercialization. Among many layered oxides, $\mathrm{P} 2-\mathrm{Na}_{2 / 3}$ $\left[\mathrm{Ni}_{1 / 3} \mathrm{Mn}_{2 / 3}\right] \mathrm{O}_{2}$ has been the focus of research because of its low cost, ease of synthesis, and high theoretical capacity of more than $250 \mathrm{mAh} \mathrm{g}^{-1}$ (Wu et al., 2015). However, an experimental study shows that the irreversible phase transition and volume change of $\mathrm{P} 2$ to $\mathrm{O} 2$ phase can be observed when charging to $4.2 \mathrm{~V}$, resulting in poor cycling stability, thereby leading to a great restriction for its practical application (Lee et al., 2013; Peng-Fei Wang et al., 2018). Under high voltage, the electrolyte is easily decomposed into hydrofluoric acid and water molecular impurities, resulting in the corrosion of active substances, which makes the cathode material unable to transport ions, and the disembedding of $\mathrm{Na}^{+}$at high voltage also destroys the crystal structure, eventually decreasing cycling stability (Tanabe et al., 2013). To enhance the cycling stability of P2-type cathode materials, many efforts have been made, such as doping transition metals (Jin et al., 2020; Zhao et al., 2020; Devendrasinh et al., 2021). For example, Wang et al. (2016) prepared $\mathrm{Mn}$ and Ni matrix $\mathrm{P} 2-\mathrm{Na}_{0.67} \mathrm{Mn}_{0.67} \mathrm{Ni}_{0.23} \mathrm{Mg}_{0.05}$ using the sol-gel method, which maintained good structural stability and retained about $85 \%$ reversible capacity after 50 cycles. Besides doping, surface modification is another effective method of improving electrochemical performance. Various metal oxides and phosphate coatings $\left[\mathrm{Al}_{2} \mathrm{O}_{3}\right.$ (Kaliyappan et al., 2015), $\mathrm{CuO}$ (Dang et al., 2019), $\mathrm{ZrO}_{2}$ (Kaliyappan et al., 2017), $\mathrm{ZnO}$ (Yang et al., 2020), $\mathrm{TiO}_{2}$ (Yu et al., 2020), $\mathrm{NaPO}_{3}$ (Jae Hyeon Jo et al., 2018), and $\mathrm{NaCaPO}_{4}$ (Chang-Heum Jo et al., 2018)] have been applied to various anodes and cathodes to achieve the application of high-performance SIBs. Kaliyappan et al. (2015) coated $\mathrm{Al}_{2} \mathrm{O}_{3}$ with different thicknesses on the surface of $\mathrm{P} 2-\mathrm{Na}_{2 / 3}\left(\mathrm{Mn}_{0.54} \mathrm{Ni}_{0.13} \mathrm{Co}_{0.13}\right) \mathrm{O}_{2}$ using atomic layer deposition technology. The samples showed good electrochemical properties. The maximum discharge

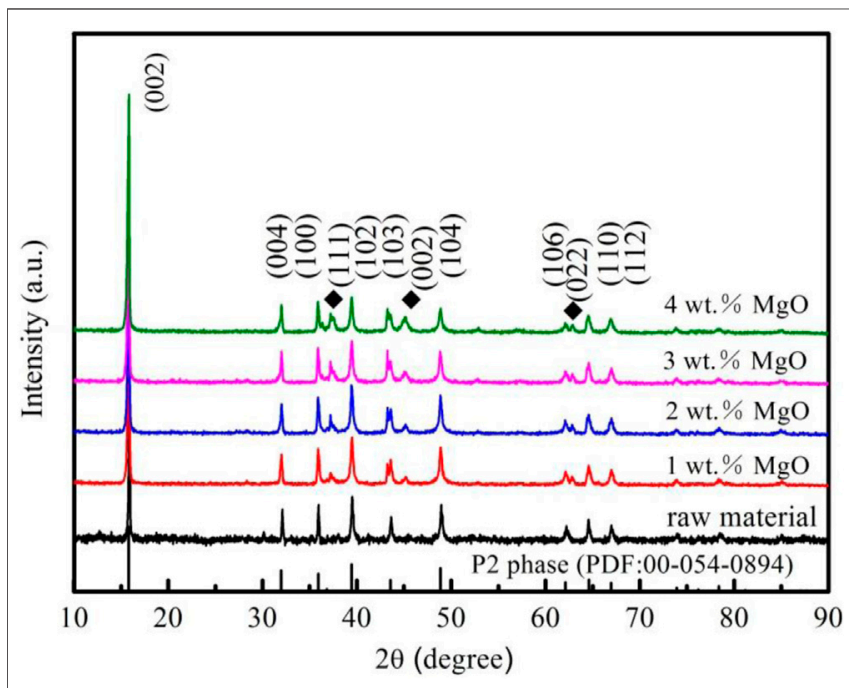

FIGURE 2 | X-ray diffraction patterns of the pristine NM and $x$ wt $\%$ MgO-modified NM $(x=1,2,3$, and 4) materials.

capacity of MNC-2 electrode material at $1 \mathrm{C}$ is $123 \mathrm{mAh} \mathrm{g}^{-1}$, and the cycling stability of the material is better than that of pristine material. $\mathrm{Al}_{2} \mathrm{O}_{3}$ coating has been proven to be able to effectively improve the cycling stability of the cathode materials. Dang et al. (2019) coated a layer of $\mathrm{CuO}$ on the surface of P2$\mathrm{Na}_{2 / 3} \mathrm{Ni}_{1 / 3} \mathrm{Mn}_{2 / 3} \mathrm{O}_{2}$, which not only improved the structural stability but also reduced the decomposition degree of the material at high potential. Electrochemical tests showed that the specific capacities of $\mathrm{Na}_{2 / 3} \mathrm{Ni}_{1 / 3} \mathrm{Mn}_{2 / 3} \mathrm{O}_{2}$ at 0.1 and $5 \mathrm{C}$ were 101 and $45 \mathrm{mAh} \mathrm{g}^{-1}$, respectively. The specific capacities of coated $\mathrm{Na}_{2 / 3} \mathrm{Ni}_{1 / 3} \mathrm{Mn}_{2 / 3} \mathrm{O}_{2}$ at the same rate were 107 and $69 \mathrm{mAh} \mathrm{g}^{-1}$, and the coated samples showed higher capacity and cycling stability. Therefore, as regards layered cathode oxide SIBs, an effective coating can reduce the contact with electrolyte, alleviate electrode dissolution, and enhance the cycling stability. 

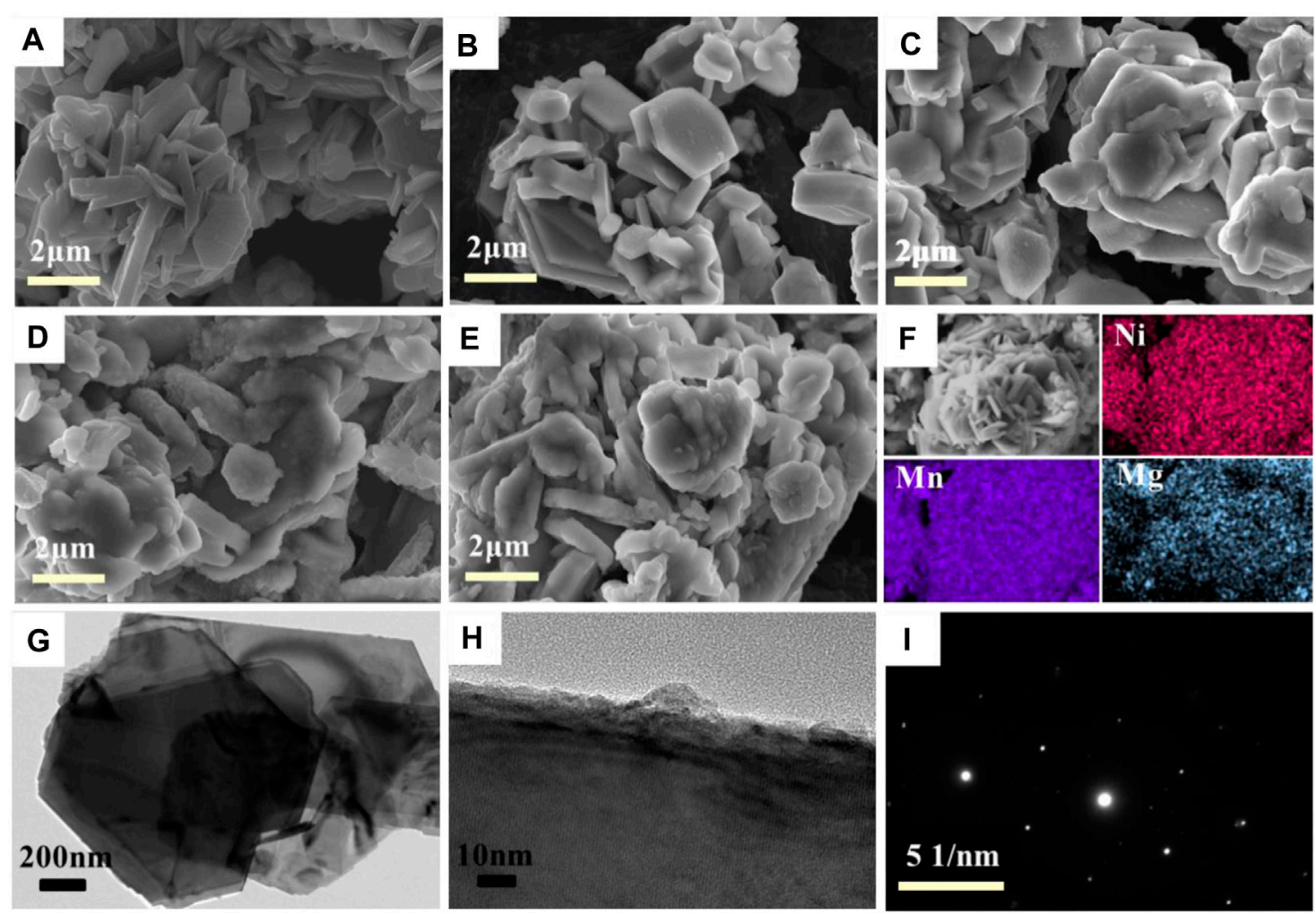

FIGURE 3 | SEM images of MgO-coated samples [(A) 0 wt\%; (B) 1 wt\%; (C) 2 wt\%; (D) 3 wt\%; (E) 4 wt\%]. (F) EDX mappings of Ni, Mn, and Mg in 2 wt\% MgOcoated samples, (G) TEM image, (H) HRTEM image, and (I) SAED patters of a single particle of $2 \mathrm{wt} \% \mathrm{MgO}$-coated samples.

In this study, the $\mathrm{Na}_{0.67} \mathrm{Ni}_{0.33} \mathrm{Mn}_{0.67} \mathrm{O}_{2}$ sample was prepared by a simple solid-state method, and a facile wet chemistry route method was used to fabricate a MgO-coated $\mathrm{Na}_{2 / 3} \mathrm{Ni}_{1 / 3} \mathrm{Mn}_{2 / 3} \mathrm{O}_{2}$ composites. $\mathrm{MgO}$ layers of various thicknesses were successfully coated onto the layered cathode oxide $\mathrm{Na}_{0.67} \mathrm{Ni}_{0.33} \mathrm{Mn}_{0.67} \mathrm{O}_{2}$, and the quantity of $\mathrm{MgO}$ was optimized. $\mathrm{MgO}$ coating significantly improves the cyclic stability and rate capability of pristine $\mathrm{Na}_{0.67} \mathrm{Ni}_{0.33} \mathrm{Mn}_{0.67} \mathrm{O}_{2}$ because it effectively alleviates electrode dissolution and stabilizes the structure of the electrode. This research demonstrates that $\mathrm{MgO}$ modification is an effective strategy for improving the electrochemical performance of layered cathode oxide and expands the potential commercial applications of layered cathode oxide.

\section{MATERIALS AND METHODS}

\section{Synthesis}

Firstly, $\mathrm{Na}_{0.67} \mathrm{Ni}_{0.33} \mathrm{Mn}_{0.67} \mathrm{O}_{2}$ (NM) was prepared by a facile solidstate reaction. Sodium carbonate, magnesium oxide, nickel oxide, and manganese oxide were mixed according to the stoichiometric ratio. The mixture with $0.3865 \mathrm{~g} \mathrm{Na}_{2} \mathrm{CO}_{3}, 0.5825 \mathrm{~g} \mathrm{MnO}_{2}$, and $0.2134 \mathrm{~g} \mathrm{NiO}$ was calcined at $900^{\circ} \mathrm{C}$ for $12 \mathrm{~h}$ to acquire the pristine $\mathrm{NM}$ sample. The $\mathrm{MgO}$ with different thicknesses was coated on NM using a facile wet chemistry route. For example, $0.053 \mathrm{~g}$ of magnesium was firstly acetated in a beaker containing $50 \mathrm{ml}$ alcohol. Then, $1 \mathrm{~g}$ of NM was added with stirring for $2 \mathrm{~h}$. The mixed solution was dried in an oven at $80^{\circ} \mathrm{C}$ for $5 \mathrm{~h}$. The dried powder was heated in air at $550^{\circ} \mathrm{C}$ for $5 \mathrm{~h}$ to obtain $1 \mathrm{wt} \% \mathrm{MgO}$ coated NM sample. The 2, 3, and $4 \mathrm{wt} \% \mathrm{MgO}$-coated $\mathrm{NM}$ samples were synthesized through the same procedure only using the different weights of magnesium.

\section{Characterization}

XRD patterns were collected on X-ray diffraction (Rigaku) with $\mathrm{Cu}$ Ka radiation $(\lambda=0.154060 \mathrm{~nm})$ within the $2 \theta$ between $10^{\circ}$ and $90^{\circ}$ at $4^{\circ}$ per minute. The evaluation of particle morphology and element distribution was performed using scanning electron microscopy (SEM; ZEISS SUPRA55). TEM (JEM2100) images were used to perform the evaluation of morphology and microstructure of cathode materials. XPS (Axis Ultra DLD) was applied to observe the valence states of $\mathrm{Ni}, \mathrm{Mn}$, and $\mathrm{Mg}$ elements. The active cathode materials were mixed uniformly with carbon black and polyvinylidene fluoride (PVDF) in $\mathrm{N}$-methyl pyrrolidone (NMP) at a mass ratio of 8:1:1. After mixing and stirring for $2 \mathrm{~h}$, the slurry was uniformly smeared onto $\mathrm{Al}$ foils and dried in a vacuum oven at $120^{\circ} \mathrm{C}$ for $10 \mathrm{~h}$. The mass loading of the active materials was about $2 \mathrm{mg} \mathrm{cm}^{-2}$. The electrolyte was $1 \mathrm{M} \mathrm{NaClO}_{4}$ dissolved in propylene carbonate/ fluoroethylene carbonate (19:1 in volume). Then, the as-prepared cathode, sodium discs (Aldrich, $>99 \%$ ), and glass fiber (Whatman) were assembled into the CR2032-type coin cell in 

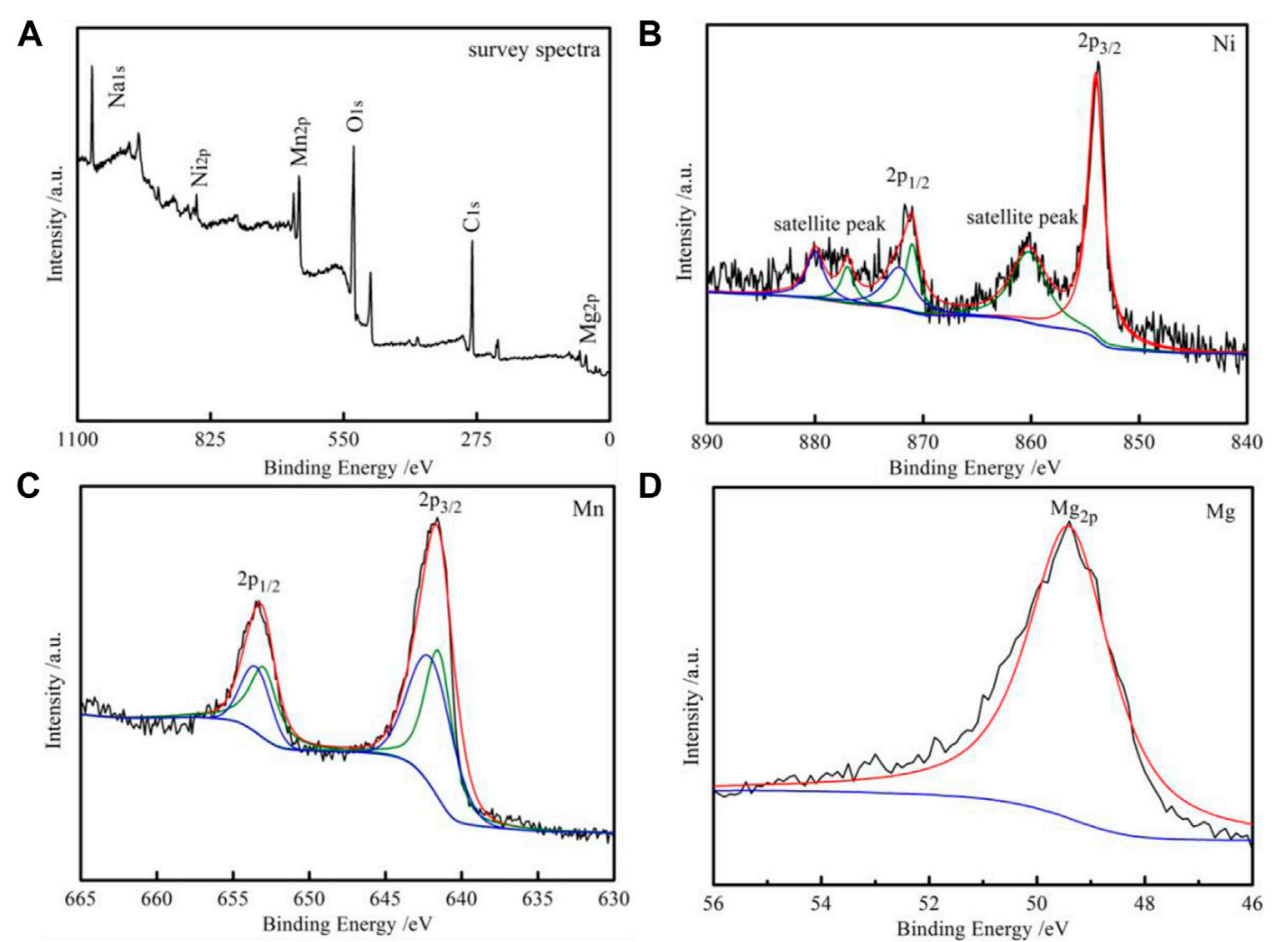

FIGURE 4 | XPS spectra of the 2 wt\% MgO-coated NM samples. (A) Full spectrum of XPS. (B) Ni 2p. (C) Mn 2p. (D) Mg 2p.

glove box. Current-voltage (CV) curves were performed on a CHI1000C electrochemical workstation (Chenhua) at a scan rate of $0.1 \mathrm{mV} \mathrm{s}^{-1}$, and electrochemical impedance spectroscopy (EIS) was measured with a voltage amplitude of $5 \mathrm{mV}$ for the scanning turns for three cycles. Charge/discharge, rate, and long-term cycling properties were analyzed by Land Instruments (Wuhan, China) in a voltage range of $2-4.5 \mathrm{~V}$ at room temperature.

\section{RESULTS AND DISCUSSION}

MgO-coated NM composites are obtained by a facile wet chemistry route method. The synthesis procedure is described in Figure 1. The NM is prepared by high-temperature solid-state process. The $\mathrm{MgO}$ coating is obtained from magnesium acetate solution to stabilize the structure of the material.

The XRD spectra of the samples are presented in Figure 2. The reflection peaks located at $15.7^{\circ}, 35.9^{\circ}$, and $43.5^{\circ}$ are consistent with the (002), (100), and (103) planes for different thicknesses of $\mathrm{MgO} / \mathrm{NM}$ cathode materials, which conforms to the $\mathrm{P} 2$ structure (JCPDS No. 00-05-0894) of electrodes. Furthermore, the peaks located at $2 \theta=37.13^{\circ}, 43.1^{\circ}$, and $62.6^{\circ}$ correspond to (111), (002), and (022) crystal planes of MgO (JCPDS No. 96-901-3247). The above results indicate that the $\mathrm{MgO}$ and $\mathrm{P} 2$ structures of $\mathrm{NM}$ cathode materials are successfully prepared.

The morphologies of samples are investigated by SEM and TEM. Figure 3A-E displays that all samples exhibit hexagonal sheets and a particle size of $\sim 1-4 \mu \mathrm{m}$. X-ray spectrometry elemental mapping is used to indicate that elements exist on the surface of NM cathode along with $\mathrm{MgO}$ in Figure 3F. TEM images (Figure 3G, $\mathbf{H}$ ) of $2 \mathrm{wt} \% \mathrm{MgO}$-coated samples show that the morphologies of secondary particles in SEM and TEM are comparable. The $\mathrm{MgO}$ surface coating is evidently observed in the high-resolution TEM images, and it can be observed that $\mathrm{MgO}$ is greatly coated on the surface with an obvious boundary between the bulk and surface. Selected area electron diffraction (SAED) images of $2 \mathrm{wt} \% \mathrm{MgO}$-coated samples are shown in Figure 3I with continuous diffraction rings, indicating the P2-type structure of samples. All results confirm that an MgO-coated layer is successfully synthesized.

XPS spectra of $2 \mathrm{wt} \% \mathrm{MgO}$-coated samples are presented in Figure 4 to analyze the valence states of elements. It can be found that there are $\mathrm{Na}, \mathrm{Mn}, \mathrm{Ni}, \mathrm{Mg}, \mathrm{C}$, and $\mathrm{O}$ elements in the entire spectrum of XPS in Figure 4A. In Figure 4B, two binding energy peaks near 854 and $871 \mathrm{eV}$ represent $\mathrm{Ni} 2 \mathrm{p}_{3 / 2}$ and $\mathrm{Ni} 2 \mathrm{p}_{1 / 2}$, implying the +2 valence state of $\mathrm{Ni}$ ion (Lin et al., 2015), and the weaker satellite peaks at $\sim 881$ and $\sim 861 \mathrm{eV}$ indicate the presence of $\mathrm{Ni}^{3+}$ (Bao et al., 2021). Two domain peaks are divided into four peaks in Figure 4C; the couple of peaks at 641 and $653 \mathrm{eV}$ represents $\mathrm{Mn}^{3+}$, whereas the couple of peaks located at 642 and $653.5 \mathrm{eV}$ can be ascribed to $\mathrm{Mn}^{4+}$ (Li et al., 2013). The spectra of Mg $2 \mathrm{p}$ observed at the binding energy of $49 \mathrm{eV}$ of the $2 \mathrm{wt} \%$ MgO-coated materials are shown in Figure 4D. The binding energy of $\mathrm{Mg}$ corresponds to $\mathrm{MgO}$, implying a +2 oxidation state for Mg (Shi et al., 2013). 

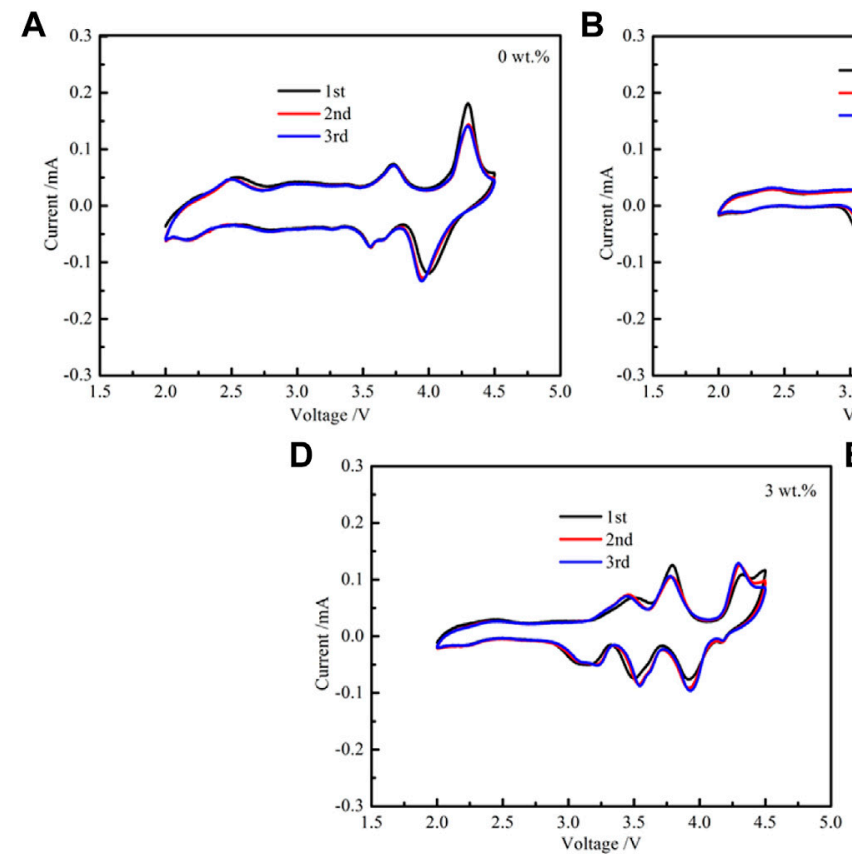
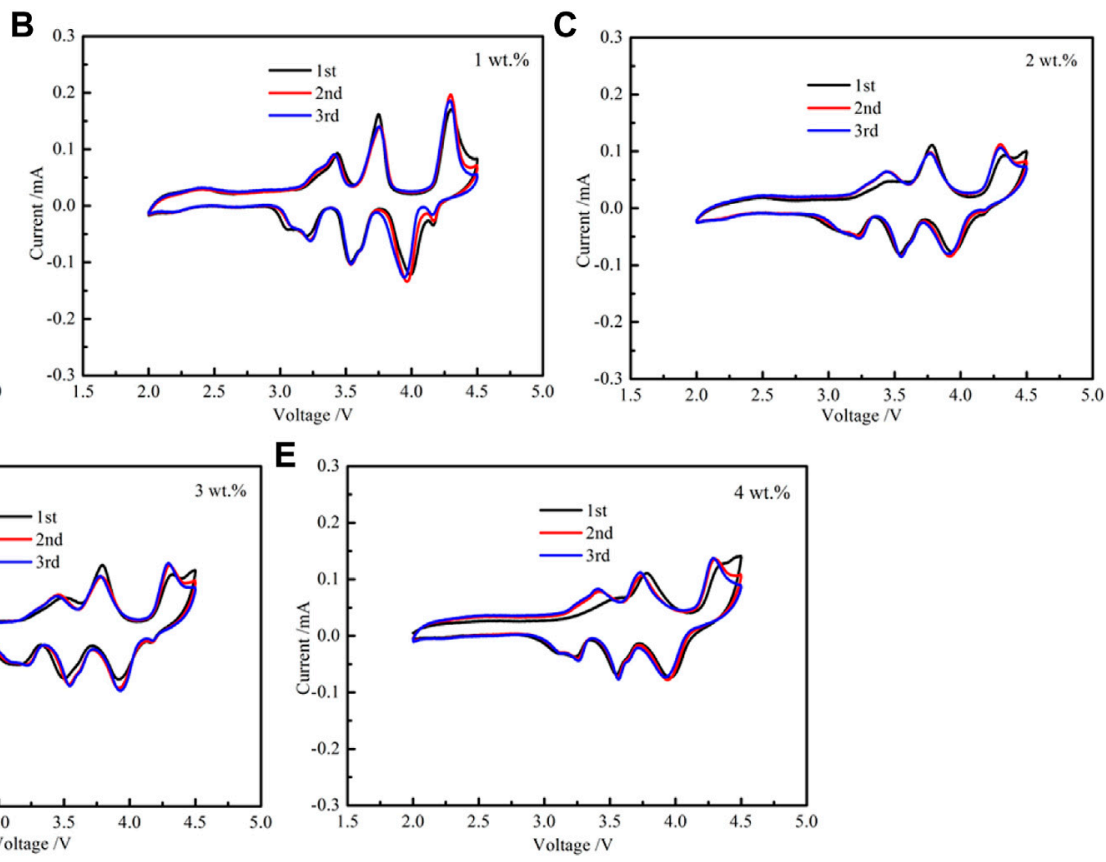

FIGURE 5 | Cyclic voltammograms of NM and MgO-coated samples. (A) NM; (B) 1 wt\%; (C) 2 wt\%; (D) 3 wt\%; (E) 4 wt\%.

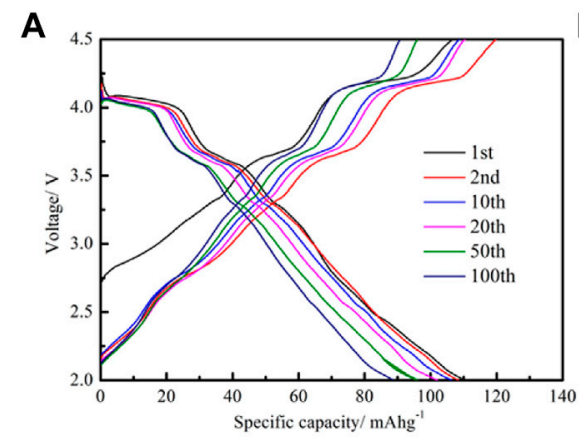

D

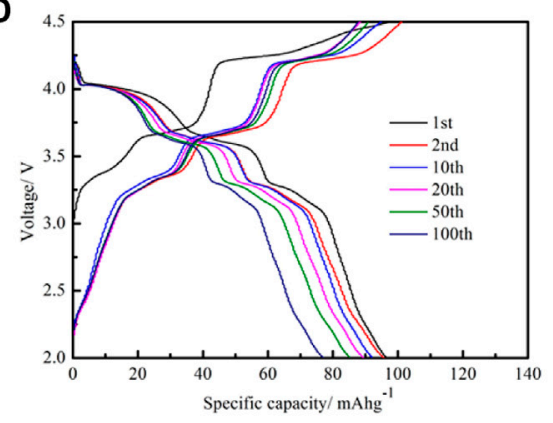

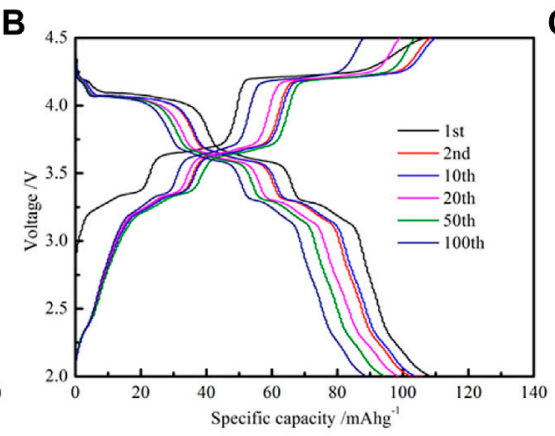

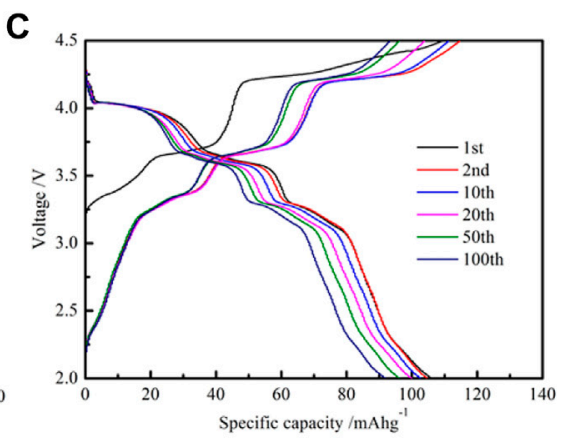

E

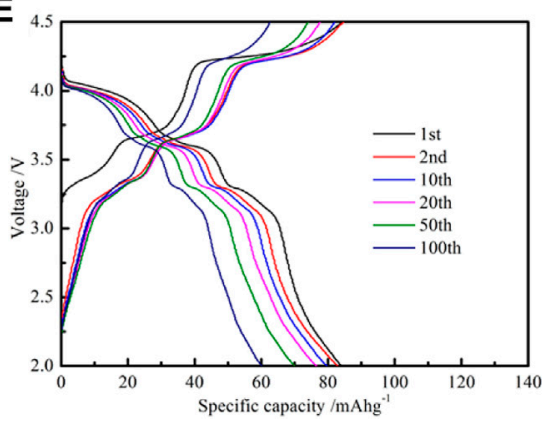

FIGURE 6 | Charge/discharge profiles of NM and MgO-coated samples. (A) NM; (B) 1 wt\%; (C) 2 wt\%; (D) 3 wt\%; (E) 4 wt\%.

Figure 5 shows the $C V$ plots of various electrodes at scanning rates of $0.1 \mathrm{mV} \mathrm{s}^{-1}$ ranging from 2 to $4.5 \mathrm{~V}$. The reversible redox peaks at 3.4/3.25 $\mathrm{V}$ and 3.75/3.5 $\mathrm{V}$ are corresponding to the redox reaction of $\mathrm{Ni}^{2+} / \mathrm{Ni}^{3+}$ and $\mathrm{Ni}^{3+} / \mathrm{Ni}^{4+}$ (Yu et al., 2017). $\mathrm{Mn}^{3+} / \mathrm{Mn}^{4+}$ peak couple are observed at low potentials $(\leq 2.4 \mathrm{~V})$ (Yuan et al.,
2013; Chen et al., 2018). The anodic/cathodic peaks at 4.25/4 V show more differences in intensity, indicating an irreversible electrochemical process, which can be related to the phase transition from P2 to O2 (Su et al., 2013; Liu et al., 2015). The $\mathrm{CV}$ curve of $2 \mathrm{wt} \%$-coated samples own the highest coincidence 

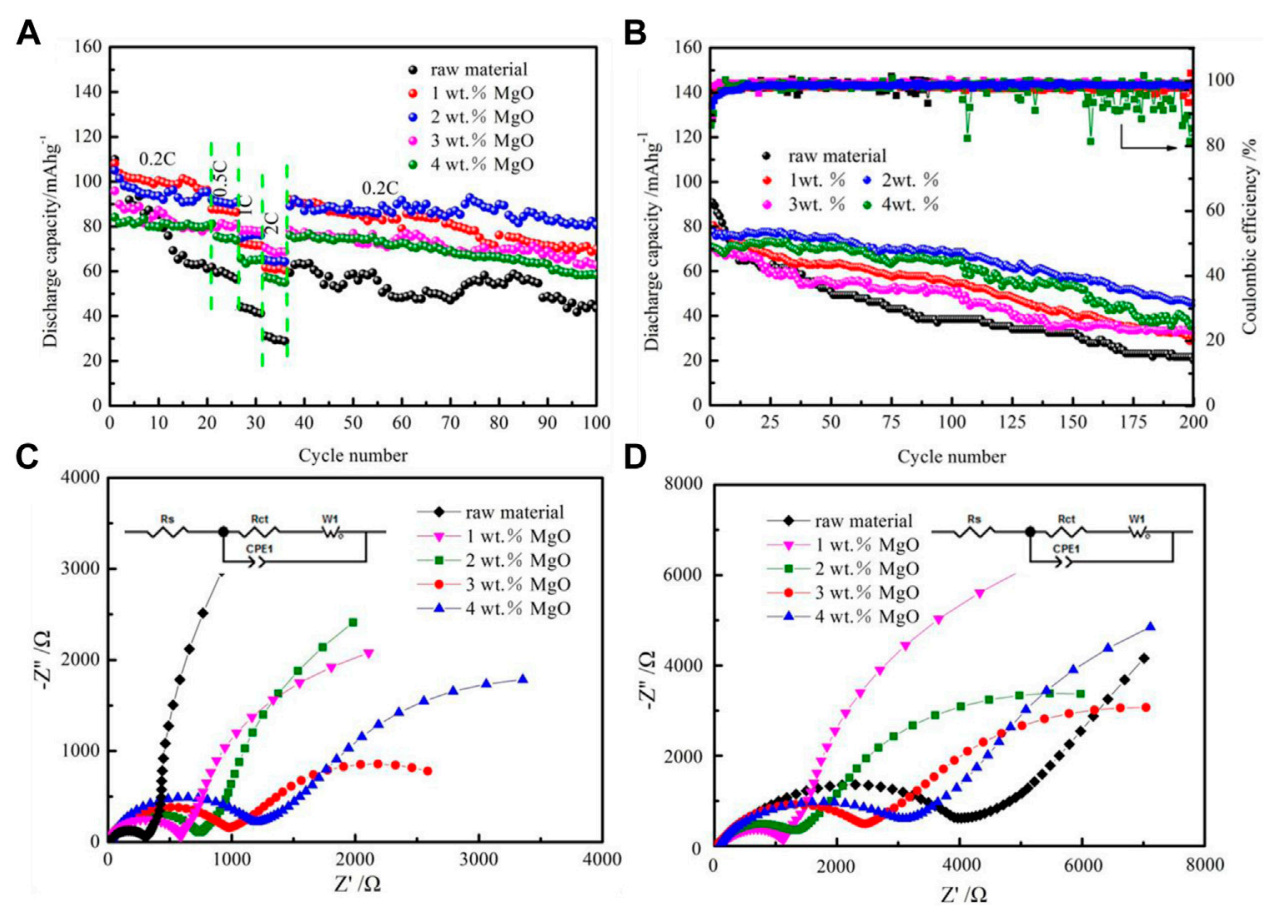

FIGURE 7 | (A) Rate and (B) long-term cycling performance and Coulombic efficiencies of NM and MgO-modified materials. Nyquist plots of samples (C) before and (D) after 200 rounds of cycling.

TABLE 1 | Comparison of initial capacity and cycling stability of layer cathodes modified by coating in recent reports.

\begin{tabular}{|c|c|c|c|c|}
\hline Electrodes & Coating layer & Initial capacity (mAh $\left.\mathrm{g}^{-1}\right)$ & Capacity retention $\left(\mathrm{mAh} \mathrm{g}^{-1}\right)$ & References \\
\hline $\mathrm{Na}_{2 / 3} \mathrm{Ni}_{1 / 3} \mathrm{Mn}_{2 / 3} \mathrm{O}_{2}$ & $\mathrm{MgO}$ & 105 & $81.5 \%$ (0.2 C 100 cycles) & This work \\
\hline $\mathrm{Na}_{2 / 3} \mathrm{Ni}_{1 / 3} \mathrm{Mn}_{2 / 3} \mathrm{O}_{2}$ & $\mathrm{CuO}$ & 107 & $70.5 \%$ (0.1 C 100 cycles) & Dang et al. (2019) \\
\hline \multirow[t]{2}{*}{$\mathrm{Na}_{0.66}\left(\mathrm{Mn}_{0.54} \mathrm{Co}_{0.13} \mathrm{Ni}_{0.13}\right) \mathrm{O}_{2}$} & $\mathrm{ZrO}_{2}$ & 122 & <50\% (1 C 100 cycles) & Kaliyappan et al. (2017) \\
\hline & $\mathrm{TiO}_{2}$ & 106 & $<50 \%$ (1 C 100 cycles) & \\
\hline $\mathrm{Na}_{2 / 3} \mathrm{Ni}_{1 / 3} \mathrm{Mn}_{2 / 3} \mathrm{O}_{2}$ & $\mathrm{ZnO}$ & 94 & $75.4 \%$ (0.5 C 200 cycles) & Yang et al. (2020) \\
\hline $\mathrm{NaMn}_{0.33} \mathrm{Fe}_{0.33} \mathrm{Ni}_{0.33} \mathrm{O}_{2}$ & $\mathrm{TiO}_{2}$ & 103.6 & 71.0\% (1 C 100 cycles) & Yu et al. (2020) \\
\hline
\end{tabular}

degree in the first 3 weeks. Compared with other samples, it shows better cyclic stability of the electrode under high voltage.

The charge and discharge tests of $\mathrm{NM}$ and $\mathrm{MgO}$-coated samples are conducted at $0.2 \mathrm{C}$ as presented in Figure 6. It is worth noting that the initial discharge capacities of pristine and MgO-NM (the $\mathrm{MgO}$ is 1, 2, 3, and $4 \mathrm{wt} \%$ ) are 110, 108, 105, 96, and $84 \mathrm{mAh} \mathrm{g}^{-1}$, respectively. Furthermore, the capacity retention rates after 100 cycles are $78.2 \%, 81.5 \%, 87.6 \%, 76 \%$, and $71.4 \%$, respectively. However, the sample has the best capacity retention when the $\mathrm{MgO}$ coating thickness is $2 \mathrm{wt} \%$ compared with other samples.

The rate properties and cycling stability are important factors affecting the commercial application of SIBs. The rate performance and cycling stability of materials are revealed in Figure 7. As a result, the capability rate of all samples is analyzed within a $2.0-4.5-\mathrm{V}$ voltage range at current densities from 0.2 to 2 C. As shown in Figure 7A, $2 \mathrm{wt} \% \mathrm{MgO}$-coated materials have the best performance rate among various materials. When the current density reaches up to $2 \mathrm{C}$, the average discharge capacity of the material is about $66 \mathrm{mAh} \mathrm{g}^{-1}$. However, after a large current density cycle, the material still remains at $89 \mathrm{mAh} \mathrm{g}^{-1}$ reversible specific capacity at $0.2 \mathrm{C}$ in the 100 th cycle, which is significantly higher than any other coated thickness samples. Figure $\mathbf{7 B}$ displays the cycling performance of the above samples at $0.5 \mathrm{C}$. The capacity of the pristine sample NM decreases the most. However, the $2 \mathrm{wt} \% \mathrm{MgO}$-coated sample exhibits an 84 $\mathrm{mAh} \mathrm{g}^{-1}$ initial discharge capacity at $0.5 \mathrm{C}$ with a capacity retention of $66.7 \%$ after 200 cycles. Based on the foregoing, when the $\mathrm{MgO}$ coating thickness is $2 \mathrm{wt} \%$, the comprehensive electrochemical performance of the material is the best. All results show that $\mathrm{MgO}$ with an appropriate thickness improves the conductivity and cycling stability of the pristine. Table $\mathbf{1}$ is listed to intuitively show the comparison of the initial capacity and cycling stability of layer cathodes modified by coating in recent reports.

The performances of conductivity and charge transport of the above electrodes are investigated using electrochemical impedance spectroscopy measurements from $100 \mathrm{kHz}$ to 


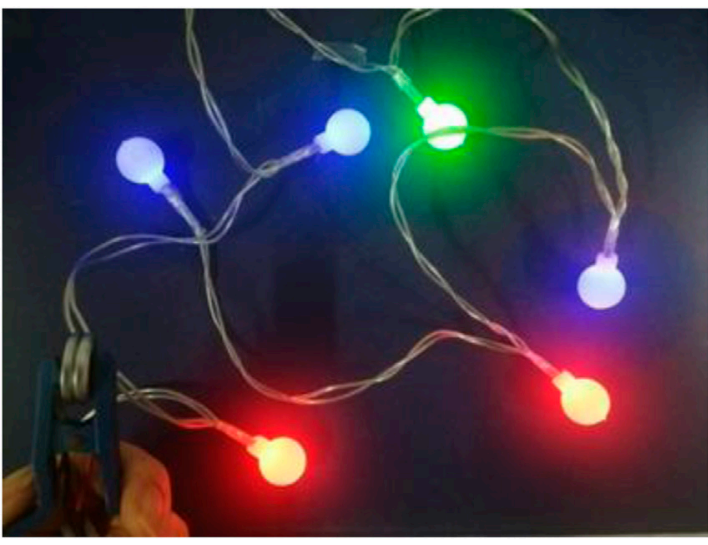

FIGURE 8 | Digital photograph of colored LEDs lighted by two 2 wt\% MgO-coated NM devices.

$0.01 \mathrm{~Hz}$ as presented in Figures 7C,D. Nyquist plots are composed of one semicircle and a sloped straight line. In the middle and high frequencies, the diameter of the impedance curve represents the charge transfer impedance (Rct). The lowest Rct values of samples indicate that they have the highest conductivity and fastest charge transfer rate. It should be noted that the Rct value of the pristine sample increases sharply. However, the growth trend of Rct has been significantly inhibited due to the existence of an $\mathrm{MgO}$ coating layer. The results suggest that a thin $\mathrm{MgO}$ coating layer can effectively alleviate electrode dissolution and prevent the formation of SEI film on the surface of the active material, so as to enhancing the long-term cycling performance of the material. Hence, considering the charge and discharge, rate, and long-term cycling performances, comprehensively, the cathodic material with $2 \mathrm{wt} \% \mathrm{MgO} / \mathrm{NM}$ has the best electrochemical performance. The $2 \mathrm{wt} \% \mathrm{MgO}$-coated $\mathrm{NM}$ was used as a cathode material to assemble a battery pack with two SIB half-batteries in series as illustrated in Figure 8. As can be seen, the battery pack can light up six small LED bulbs. The result confirms that the as-prepared $\mathrm{MgO}$-coated cathode materials have excellent electrochemical properties and practical application ability.

\section{REFERENCES}

Bao, S., Huang, Y.-y., Wang, J.-z., Luo, S.-h., Su, G.-q., and Lu, J.-l. (2021). Highoperating Voltage, Long-Life Layered Oxides for Sodium Ion Batteries Enabled by Cosubstitution of Titanium and Magnesium. ACS Sust. Chem. Eng. 9, 2534-2542. doi:10.1021/acssuschemeng.0c08174

Chang-Heum Jo, C.-H., Jo, J.-H., Yashiro, H., Kim, S.-J., Sun, Y.-K., and Myung, S.-T. (2018). Bioinspired Surface Layer for the Cathode Material of HighEnergy-Density Sodium-Ion Batteries. Adv. Energ. Mater. 8, 1702942. doi:10. 1002/aenm.201702942

Chen, T., Liu, W., Gao, H., Zhuo, Y., Hu, H., Chen, A., et al. (2018). A P2-type Na0.44Mn0.6Ni0.3Cu0.1O2 Cathode Material with High Energy Density for Sodium-Ion Batteries. J. Mater. Chem. A. 6, 12582-12588. doi:10.1039/c8ta04791j

\section{CONCLUSION}

In this paper, the layered cathode oxide material of NM was synthesized by a simple solid-state method. Different-thickness $\mathrm{MgO} / \mathrm{NM}$ were further synthesized by using a facile wet chemistry route as the electrode material of SIBs. Owing to the presence of an $\mathrm{MgO}$ coating layer on the surface of NM cathode materials, which prevents direct contact with electrolyte, stabilizes the surface structure, and effectively improves the electrochemical performance of the pristine material, the results of electrochemical test show that the cycling stability and rate capability are greatly improved. The $2 \mathrm{wt} \% \mathrm{MgO}$-coated cathode has a smaller Rct value, superior rate properties, and high cycling stability. Therefore, $\mathrm{MgO}$ modification is an effective strategy for layered cathode oxide and a promising candidate for practical applications in next-generation sodium batteries.

\section{DATA AVAILABILITY STATEMENT}

The original contributions presented in the study are included in the article/Supplementary Material; further inquiries can be directed to the corresponding authors.

\section{AUTHOR CONTRIBUTIONS}

LX: investigation and writing-original draft. SB: conceptualization and formal analysis. LY: data curation. YZ: formal analysis. JL: methodology, supervision, and writing-review and editing. YY: supervision. All authors contributed to the article and approved the submitted version.

\section{FUNDING}

This work was supported by the National Natural Science Foundation, China (52071091, 52004121, and 52001081); the Open Program of State Key Laboratory of Metal Material for Marine Equipment and Application (SKLMEA-K202007); and the Outstanding Young Talents Program of University of Science and Technology Liaoning (2021YQ01).

Dang, R., Li, Q., Chen, M., Hu, Z., and Xiao, X. (2019). CuO-Coated and Cu2+Doped Co-modified P2-type Na2/3[Ni1/3Mn2/3] O2 for Sodium-Ion Batteries. Phys. Chem. Chem. Phys. 21, 314-321. doi:10.1039/c8cp06248j

Devendrasinh, D., Reddy, M. V., and Indranil, B. (2021). Understanding the Effect of $\mathrm{Zn}$ Doping on Stability of Cobalt-free P2- $\mathrm{Na}_{0.60} \mathrm{Fe}_{0.5} \mathrm{Mn}_{0.5} \mathrm{O}_{2}$ Cathode for Sodium Ion Batteries. Electrochem 2, 323-334. doi:10.3390/ electrochem 2020023

Du, G., and Pang, H. (2021). Recent Advancements in Prussian Blue Analogues: Preparation and Application in Batteries. Energ. Storage Mater. 36, 387-408. doi:10.1016/j.ensm.2021.01.006

Essehli, R., Alkhateeb, A., Mahmoud, A., Boschini, F., Ben Yahia, H., Amin, R., et al. (2020). Optimization of the Compositions of Polyanionic Sodium-Ion Battery Cathode NaFe2-xVx(PO4)(SO4)2. J. Power Sourc. 469, 228417. doi:10. 1016/j.jpowsour.2020.228417 
González, A., Goikolea, E., Barrena, J. A., and Mysyk, R. (2016). Review on Supercapacitors: Technologies and Materials. Renew. Sust. Energ. Rev. 58, 1189-1206. doi:10.1016/j.rser.2015.12.249

Hakim, C., Sabi, N., and Saadoune, I. (2021). Mixed Structures as a New Strategy to Develop Outstanding Oxides-Based Cathode Materials for Sodium Ion Batteries: A Review. J. Energ. Chem. 61, 47-60. doi:10.1016/j.jechem.2021.02.027

Huang, Y., Fang, C., Zeng, R., Liu, Y., Zhang, W., Wang, Y., et al. (2017). In SituFormed Hierarchical Metal-Organic Flexible Cathode for High-Energy SodiumIon Batteries. Chemsuschem 10, 4704-4708. doi:10.1002/cssc.201701484

Jae Hyeon Jo, J. H., Choi, J. U., Konarov, A., Yashiro, H., Yuan, S., Shi, L., et al. (2018). Sodium-Ion Batteries: Building Effective Layered Cathode Materials with Long-Term Cycling by Modifying the Surface via Sodium Phosphate. Adv. Funct. Mater. 28, 1705968. doi:10.1002/adfm.201705968

Jin, T., Wang, P. F., Wang, Q. C., Zhu, K., Deng, T., Zhang, J., et al. (2020). Realizing Complete Solid-Solution Reaction in High Sodium Content P2-type Cathode for High-Performance Sodium-Ion Batteries. Angew. Chem. Int. Ed. 59, 14511-14516. doi:10.1002/anie.202003972

Kaliyappan, K., Liu, J., Lushington, A., Li, R., and Sun, X. (2015). Highly Stable $\mathrm{Na} 2 / 3$ (Mn0.54Ni0.13Co0.13)O2Cathode Modified by Atomic Layer Deposition for Sodium-Ion Batteries. ChemSusChem 8, 2537-2543. doi:10. 1002/cssc.201500155

Kaliyappan, K., Liu, J., Xiao, B., Lushington, A., Li, R., Sham, T.-K., et al. (2017). Enhanced Performance of P2-Na0.66 (Mn0.54 Co0.13 Ni0.13 )O2 Cathode for Sodium-Ion Batteries by Ultrathin Metal Oxide Coatings via Atomic Layer Deposition. Adv. Funct. Mater. 27, 1701870-1701877. doi:10.1002/adfm.201701870

Kannan, K., Kouthaman, M., Arjunan, P., Priyanka, V., Subadevi, R., Kumaresan, L., et al. (2021). Iron Substituted Layered P2-type Na1/2Ti6/10Ni3/10Fe1/10O2 as Innovative Anode Material for Rechargeable Sodium Batteries. Inorg. Chem. Commun. 124, 108383. doi:10.1016/j.inoche.2020.108383

Kuan Wang, K., Yan, P., and Sui, M. (2018). Phase Transition Induced Cracking Plaguing Layered Cathode for Sodium-Ion Battery. Nano Energy 54, 148-155. doi:10.1016/j.nanoen.2018.09.073

Kundu, D., Talaie, E., Duffort, V., and Nazar, L. F. (2015). The Emerging Chemistry of Sodium Ion Batteries for Electrochemical Energy Storage. Angew. Chem. Int. Ed. 54, 3431-3448. doi:10.1002/chin.2015213091

Lee, D. H., Xu, J., and Meng, Y. S. (2013). An Advanced Cathode for Na-Ion Batteries with High Rate and Excellent Structural Stability. Phys. Chem. Chem. Phys. 15, 3304-3312. doi:10.1039/c2cp44467d

Li, J., Xiong, S., Liu, Y., Ju, Z., and Qian, Y. (2013). Uniform LiNi1/3Co1/3Mn1/ $3 \mathrm{O} 2$ Hollow Microspheres: Designed Synthesis, Topotactical Structural Transformation and Their Enhanced Electrochemical Performance. Nano Energy 2, 1249-1260. doi:10.1016/j.nanoen.2013.06.003

Lin, C., Zhang, Y., Chen, L., Lei, Y., Ou, J., Guo, Y., et al. (2015). Hydrogen Peroxide Assisted Synthesis of $\mathrm{LiNi1} / 3 \mathrm{Co} 1 / 3 \mathrm{Mn} 1 / 3 \mathrm{O} 2$ as High-Performance Cathode for Lithium-Ion Batteries. J. Power Sourc. 280, 263-271. doi:10.1016/j.jpowsour. 2015.01.084

Liu, G., Wen, L., Li, Y., and Kou, Y. (2015). Synthesis and Electrochemical Properties of P2-Na2/3Ni1/3Mn2/3O2. Ionics 21, 1011-1016. doi:10.1007/ s11581-014-1249-2

Lu, L., Han, X., Li, J., Hua, J., and Ouyang, M. (2013). A Review on the Key Issues for Lithium-Ion Battery Management in Electric Vehicles. J. Power Sourc. 226, 272-288. doi:10.1016/j.jpowsour.2012.10.060

Lv, Z., Ling, M., Yue, M., Li, X., Song, M., Zheng, Q., et al. (2021). Vanadium-based Polyanionic Compounds as Cathode Materials for Sodium-Ion Batteries: Toward High-Energy and High-Power Applications. J. Energ. Chem. 55, 361-390. doi:10.1016/j.jechem.2020.07.008

Peng, L., Zhu, Y., Chen, D., Ruoff, R. S., and Yu, G. (2016). Two-Dimensional Materials for Beyond-Lithium-Ion Batteries. Adv. Energ. Mater. 6, 1600025. doi:10.1002/aenm.201600025

Peng-Fei Wang, P.-F., Yao, H.-R., Liu, X.-Y., Yin, Y.-X., Zhang, J.-N., Wen, Y., et al. (2018). Na +/vacancy Disordering Promises High-Rate Na-Ion Batteries. Sci. Adv. 4, eaar6018. doi:10.1126/sciadv.aar6018

Pu, X., Wang, H., Zhao, D., Yang, H., Ai, X., Cao, S., et al. (2019). Recent Progress in Rechargeable Sodium-Ion Batteries: toward High-Power Applications. Small 15, 1805427. doi:10.1002/smll.201805427

Rong, X., Qi, X., Lu, Y., Wang, Y., Li, Y., Jiang, L., et al. (2019). A New Tin-Based O3-Na0.9[Ni0.45-/2Mn Sn0.55-/2] O2 as Sodium-Ion Battery Cathode. J. Energ. Chem. 31, 132-137. doi:10.1016/j.jechem.2018.05.019
Shi, S. J., Tu, J. P., Tang, Y. Y., Liu, X. Y., Zhang, Y. Q., Wang, X. L., et al. (2013). Enhanced Cycling Stability of $\mathrm{Li}[\mathrm{Li} 0.2 \mathrm{Mn} 0.54 \mathrm{Ni} 0.13 \mathrm{Co} 0.13] \mathrm{O} 2$ by Surface Modification of $\mathrm{MgO}$ with Melting Impregnation Method. Electrochimica Acta 88, 671-679. doi:10.1016/j.electacta.2012.10.111

Su, D., Wang, C., Ahn, H.-j., and Wang, G. (2013). Single Crystalline $\mathrm{Na} 0.7 \mathrm{MnO} 2 \mathrm{Nanoplates}$ as Cathode Materials for Sodium-Ion Batteries with Enhanced Performance. Chem. Eur. J. 19, 10884-10889. doi:10.1002/chem. 201301563

Tanabe, D., Shimono, T., Kobayashi, W., and Moritomo, Y. (2013). Na-site Energy of P2-type NaxMO2(M= Mn and Co). Phys. Status Solidi RRL 7, 1097-1101. doi:10.1002/pssr.201308101

Wang, S., Wang, L., Zhu, Z., Hu, Z., Zhao, Q., and Chen, J. (2014). All Organic Sodium-Ion Batteries with Na4C8H2O6. Angew. Chem. Int. Ed. 53, 5892-5896. doi:10.1002/anie.201400032

Wang, P.-F., You, Y., Yin, Y.-X., Wang, Y.-S., Wan, L.-J., Gu, L., et al. (2016). Suppressing the P2-O2 Phase Transition of Na0.67 Mn0.67 Ni0.33 O2 by Magnesium Substitution for Improved Sodium-Ion Batteries. Angew. Chem. Int. Ed. 55, 7445-7449. doi:10.1002/anie.201602202

Wu, X., Guo, J., Wang, D., Zhong, G., McDonald, M. J., Yang, Y., et al. (2015). P2type Na $0.66 \mathrm{Ni}$ 0.33-x Zn X Mn $0.67 \mathrm{O} 2$ as New High-Voltage Cathode Materials for Sodium-Ion Batteries. J. Power Sourc. 281, 18-26. doi:10.1016/j. jpowsour.2014.12.083

Yang, Y., Dang, R., Wu, K., Li, Q., Li, N., Xiao, X., et al. (2020). Semiconductor Material ZnO-Coated P2-type Na2/3Ni1/3Mn2/3O2 Cathode Materials for Sodium-Ion Batteries with Superior Electrochemical Performance. J. Phys. Chem. C 124, 1780-1787. doi:10.1021/acs.jpcc.9b08220

Yang, Y., and Wei, W.-F. (2020). Electrochemical Mechanism of High Na-Content P2-type Layered Oxides for Sodium-Ion Batteries. Rare Met. 39, 332-334. doi:10.1007/s12598-020-01403-7

Yu, T.-Y., Hwang, J.-Y., Aurbach, D., and Sun, Y.-K. (2017). Microsphere Na0.65 [Ni0.17Co0.11Mn0.72] O2 Cathode Material for High-Performance SodiumIon Batteries. ACS Appl. Mater. Inter. 9, 44534-44541. doi:10.1021/acsami. $7 \mathrm{~b} 15267$

Yu, Y., Kong, W., Li, Q., Ning, D., Schuck, G., Schumacher, G., et al. (2020). Understanding the Multiple Effects of $\mathrm{TiO} 2$ Coating on NaMn0.33Fe0.33Ni0.33O2 Cathode Material for Na-Ion Batteries. ACS Appl. Energ. Mater. 3, 933-942. doi:10.1021/acsaem.9b02021

Yuan, D., He, W., Pei, F., Wu, F., Wu, Y., Qian, J., et al. (2013). Synthesis and Electrochemical Behaviors of Layered Na0.67[Mn0.65Co0.2Ni0.15] O2 Microflakes as a Stable Cathode Material for Sodium-Ion Batteries. J. Mater. Chem. A. 1, 3895-3899. doi:10.1039/c3ta01430d

Zhao, C., Wang, Q., Yao, Z., Wang, J., Sánchez-Lengeling, B., Ding, F., et al. (2020). Rational Design of Layered Oxide Materials for Sodium-Ion Batteries. Science 370, 708-711. doi:10.1126/science.aay9972

Zhao, X., Fan, L.-Z., and Zhou, Z. (2021). Cationic Potential: An Effective Descriptor for Rational Design of Layered Oxides for Sodium-Ion Batteries. Green. Energ. Environ. 6, 455-457. doi:10.1016/j.gee.2020.11.022

Zhu, Y., Wang, B., Gan, Q., Wang, Y., Wang, Z., Xie, J., et al. (2019). Selective Edge Etching to Improve the Rate Capability of Prussian Blue Analogues for Sodium Ion Batteries. Inorg. Chem. Front. 6, 1361-1366. doi:10.1039/c9qi00090a

Conflict of Interest: The authors declare that the research was conducted in the absence of any commercial or financial relationships that could be construed as a potential conflict of interest.

Publisher's Note: All claims expressed in this article are solely those of the authors and do not necessarily represent those of their affiliated organizations, or those of the publisher, the editors, and the reviewers. Any product that may be evaluated in this article, or claim that may be made by its manufacturer, is not guaranteed or endorsed by the publisher.

Copyright (c) 2022 Xue, Bao, Yan, Zhang, Lu and Yin. This is an open-access article distributed under the terms of the Creative Commons Attribution License (CC BY). The use, distribution or reproduction in other forums is permitted, provided the original author(s) and the copyright owner(s) are credited and that the original publication in this journal is cited, in accordance with accepted academic practice. No use, distribution or reproduction is permitted which does not comply with these terms. 